\title{
Financial Crisis and Banks Corporate Governance: The Regulatory Response
}

\author{
Francesca Battaglia \\ Università degli Studi di Napoli Parthenope \\ Italy \\ Marika Carboni \\ Università degli Studi Roma Tre \\ Italy
}

\begin{abstract}
The recent crisis has pointed out the need to re-examine the adequacy of the banks corporate governance principles in order to evaluate whether additional guidance and clarification are necessary referring to particular key areas. We aim to assess if the regulatory response to the banking corporate governance failures has been adequate. Our findings show that the regulatory intervention, led both to non-binding rules developed by international organizations, and binding rules issued by regulatory authorities, has been mainly guided by the idea that financial institutions are systemically relevant. Secondly, we outline that another common choice has been a prompt regulatory response in order to overcome the main corporate governance weaknesses developed during the crisis, with a specific focus on remuneration policies and risk management. Thirdly, it is possible to conclude that, observing the more recent regulatory interventions dealing with corporate governance after the global financial crisis, a rule-based approach is prevailing on the lighter principle-based approach.
\end{abstract}

Keywords: corporate governance, financial crisis, regulation, financial institutions, EU legislator, international organizations

\section{Introduction}

As outlined by the Financial Stability Board (FSB) in the Thematic Review on Risk Governance (2013), among other deficiencies, the recent financial crisis showed a number of governance weaknesses in the financial services industry that contribute to its excessive risk-taking. In particular, several reports ${ }^{\mathrm{a}}$, written in the wake of the financial crisis, emphasize the relevance of the following five aspects of the corporate governance: the remuneration and incentive systems, the risk management practices, the deficiencies concerning the bank board role and performance and transparency and disclosure.

In this paper, we focus on the main failures and shortcomings of banks' Internal Corporate Governance (ICG), as defined in the EBA Guidelines on Internal Governance (2011). We specify that while corporate governance is a wide concept, described as the set of relationships between an institution, its management, its shareholders and other stakeholders, Internal Governance is a key component of corporate governance, focusing on the internal structure and organization of an institution, the management body and its supervisory function, the risk management and the internal control framework. As a result, our focus does not cover the roles of external auditors, shareholders or other external stakeholders.

Generally, referring to the remuneration and incentive schemes, several features have to be considered. First of all, even if the "pay for performance" concept has generally been supported by the shareholders, it is difficult to achieve in practice. It is very common to link executive remuneration and incentives to benchmarks that have very little to do with the executive performance, such as the level of a firm's share price and not the relative position of the company. Secondly, even if executive pay should be the result of an optimal contract structure, balancing the opposing interests of managers and shareholders, managers influence over the level and the conditions for their remuneration. So, as a result, remuneration schemes show a low pay-per-performance sensitivity and are often asymmetric with a limited downside risk.

${ }^{a}$ See OECD (2009, 2010) ; Kirkpatrick G. (2009) ; European Commission (2010a, 2010b), Basel Committee (2010). 
Moreover, they need a higher level of transparency by the firm; both to explain the structure of the compensation and to correctly disclose the process build out by the company in order to define this structure. As suggested by several reports dealing with "lessons from the financial crisis", remunerations systems need to be restructured in order to promote long-term performance and set up a balance between fixed and variable components. A more relevant role should be played by non-executive independent board members in redesigning remuneration schemes, which should also be undergone to the approval of the annual meeting ("say on pay" regulation).

With reference to the risk management practices, a key finding is that an excessive risk-taking could come from the implementation of inadequate risk management models, which do not price risk correctly because of unrealistic hypotheses causing unreliable estimates. Moreover, a number of circumstances has exacerbated this situation: the risk was not managed at firm level, but rather by product or market lines; risk managers did not play a central role in the implementation of the firm's strategy; boards ignored in many cases the risk facing by the company because the information about risk exposure did not always reach top management or because it was not fully understood, due to the lack of banking and financial expertise. In addition, the risk management function has not been given appropriate weight in the decision-making process. The lesson to be learned is not to eliminate the risk since it is the core business of banking, but rather to understand, manage and communicate it.

Referring to the role played by several boards of financial and non-financial firms during the financial turmoil, the main concern deals with their qualification and their performance, both in terms of efficiency and effectiveness and resulting in the creation of competent boards, capable of objective and independent judgment. In many cases, risk oversight by boards was inadequate, often due to insufficient time commitment, inadequate technical knowledge or insufficient diversity in board composition. Moreover, as we have previously underlined, boards were often not sufficiently involved in the overall risk strategy or did not spend sufficient time discussing risk issues, as risk management was considered a low priority compared to other concerns.

In particular, they should aim at the formal independence of a (large) portion of board members and at promoting their competence through the implementation of continuous training programs, complemented by periodic, externally facilitated board evaluations. The process and general results of evaluations should be disclosed to shareholders. In addition, it is regarded as a good practice the separation of the role of the chief executive and chairman, as it can help to achieve an appropriate balance of power, increase accountability and improve the board's capacity for decision making, that should be independent fromthe management.

The complexity and the opacity of bank structure is a relevant impediment to good governance in banking. Specifically, both the implementation of an appropriate group-wide risk policy and bank governance and the avoidance of conflicts of interest and inappropriate measures taken by the major shareholders increase if the structure of the bank is complex or opaque.

To summarize, since the recent crisis has pointed out the need to re-examine the adequacy of the banks corporate governance principles in order to evaluate whether additional guidance and clarification are necessary referring to particular key areas, we aim to assess if the regulatory responses, including also the development of best practices and non-compulsory guidelines, to the banking corporate governance failures has been adequate. In detail, Section 2 analyses the regulatory response to the financial crisis focusing on non-binding guidelines issued from international organizations (i.e. EBA, BCBS, FSB and OECD), while Section 3 examines the response from the EU legislator. Section 4 concludes.

\section{The Regulatory Framework after the Financial Crisis: Non-Binding Guidelines from International Organizations}

In response to banks' internal corporate governance shortcomings highlighted by the financial crisis, a number of initiatives has been taken by several international organizations: new corporate governance and risk management principles have been issued by the Basel Committee on Banking Supervision (BCBS 2010; BCBS 2014), the European Banking Authority (hereafter EBA) published new guidelines on Internal Governance (EBA, 2011) and the Organization for Economic Co-operation and Development (hereafter OECD)provided a new edition of the 2004 version of the Principles of Corporate Governance (OECD, 2004; OECD, 2015). The objective of this section is not to provide a comprehensive and detailed analysis of this new regulatory framework, but to provide an overview of its main content in the aftermath of the financial crisis, in order to understand the main changes. 
Since regulators have focused their attention on corporate structure and organization, management body, risk management, internal control system and continuity and transparency, in this section we will analyze the abovementioned issues.

It is possible to assert that the guidelines proposed by international organizations, irrespective of the specific entity that issued them, show some common characteristics:

- they are not binding, but they have become a relevant reference for regulators and supervisors;

- they are projected to align the interest of managers and shareholders, by taking into consideration also other stakeholders, such as policyholders, employees, debt-holders, etc.;

- they aim at reducing perverse incentives towards excessive risk-taking;

- they do not prescribe strict requisites for each corporate governance issue; e.g., they do not require a particular model and structure of the boards or a specific design for remuneration schemes.

\subsection{The EBA "Guidelines on Internal Governance"}

The Guidelines of September 2011 are an update of the former "Committee of European Banking Supervisors (CEBS) Guidelines" of 2009 and 2010 (CEBS 2009; CEBS 2010). With this document, the EBA aims at improving internal governance in the banking system and observes that its deficiencies, "while not a direct trigger for the financial crisis, were closely associated with it and so were a key contributory factor." (EBA 2011, p. 7). The Guidelines focus on internal governance and do not deal with external auditors, shareholders and other external stakeholders.

Before going on in the discussion, it is necessary to clarify that in the document the EBA uses the term management body to embrace all possible governance structures. This concept is irrespective of the specific legal structure applicable to an institution in its Member State, because the aim of the Guidelines is to ensure that a particular task or responsibility is carried out, regardless of the fact that it falls within the management body or supervisory function. Consequently, the term management body stands both for board and senior management. Anyway, as pointed out by Hopt (2013), much of the text refers to the one-tier system and it addresses to the dual system specifically only when it is stated that the formal separation into two bodies is not enough for guaranteeing the objectivity and independence of the supervisory body, which still need to be assured by a suitable selection of independent members. Referring to this concern, the EBA underlines that in the one-tier system the chair and the CEO should not be the same person or, if otherwise, there should be, for example, a lead senior independent director.

The new EBA Guidelines, consistently with European and BCBS frameworks, provide 30 principles, dealing with banks and focusing on the following topics: corporate structure and governance, management body, risk management, internal control, system and continuity, transparency. Below, we summarize the principles issued for each of the above-mentioned issues.

Referring to the corporate structure and organization, the main weakness of corporate structure and organization pertains both to the complexity of institutions, not sufficiently counterbalanced by appropriate internal governance provisions, and to the sophistication and riskiness of products and services offered by cross-border groups. In order to manage the weaknesses identified within the survey regarding complex structures, the EBA introduces the "know-your-structure" principle, according to which the management body should fully know and understand the operational structure of its institution and guarantee that it meets its business strategy and risk profile. The Guidelines opt for checks and balances at group level. The parent's management body has overall responsibility for adequate internal governance across the group, while the management body of a regulated subsidiary must follow, "unless legal or supervisory requirements or proportionality considerations determine otherwise",

The Guidelines contain many principles and rules relating to the management body. They include, for example, the duties and responsibilities of this body, the assessment of the internal governance framework, the management and the supervisory functions of the management body, its composition and functioning, succession planning, independence, conflicts of interest, organization, specialized committees, outsourcing and remuneration policies. Adequate internal alert procedures must be taken by the management body to communicate internal governance concerns from the staff, whose confidentiality must be respected.

\footnotetext{
${ }^{\mathrm{b}}$ EBA Guidelines, II. 5, p. 17.
} 
We specify that even if the Guidelines on Internal Governance deal with expertise, qualification and independence, the Guidelines on the Assessment of the Suitability of Members of the Management Body and Key Function Holders of 22 November 2012 analyze in much more detail the processes, Criteria and minimum requirements for assessing the suitability of members of the management body and of key function holders of a credit institution. To this respect, we underline that the proposed Guidelines are not limited to the members of the management body in its management function, but also in its supervisory function (i.e. the criteria are also to apply to supervisory board members); furthermore, they also refer to key function holders, who play a fundamental role in the daily management of the business.

Referring to the risk management and internal control features, the Guidelines are consistent with the three-linesof-defence model, based on risk management (first line), internal control (second line)and internal audit function (third line). The control functions (including the risk control function, the compliance function and the internal audit function) must be organizationally independent from the units they control. The terms risk tolerance and risk appetite are both used to describe the absolute risks the bank is a priori open to take and the actual limits the institution pursues. Specialized committees of the management body are not mandatory, but the audit committee and the risk committee are set out much more specifically. The Guidelines makes a clear distinction between risk management and internal control.

As regards risk management, a key element of the institution's risk management is represented by its risk culture, that has to be developed through policies, examples, communication and training of staff, regarding their responsibilities for risk. A holistic view of all relevant risks (financial and non-financial, on and off balance sheet, and whether or not contingent or contractual) is important for risk management. The EBA document clearly addresses to concentration, reputational, compliance and strategic risks, that must be estimated bottom up and top down. Remuneration must be aligned to the risk profile. Specific provisions of the Guidelines refer to the risk management framework, forward and backward-looking tools and new products in particular, among which a well-documented new product approval policy (NPAP) is considered to be necessary. It is important to note that the EBA guidelines do not have the legal status of binding law; however, as they set out the EBA's view of appropriate supervisory practices, the EBA expects all competent authorities and financial markets participants to whom the Guidelines apply to comply with them, unless otherwise stated.

\subsection{The new regulatory guidelines of the Basel Committee on Banking Supervision}

The "Principles for enhancing corporate governance" published by the Basel Committee on Banking Supervision (the "Committee") in 1999 and revised in 2006, can be considered as one of the first systematic attempts to develop comprehensive regulatory principles on how to have prudent and effective corporate governance in banking $^{c}$. Nevertheless, these pre-crisis guidelines were largely disregarded and allowed too much flexibility for banks to implement remuneration policies, mainly based on short-term performance maximization, thus increasing the risk appetite of banks' managers.

To address the bank corporate governance shortcomings arising from the financial crisis, in October 2010 the Committee published a new and more comprehensive set of principles in order to enhance sound corporate governance practices at banking institutions. The aim of these principles is to build up best practices to be widely applicable in banking institutions, independent from corporate and board structures and according to their size, complexity and risk profile. On July 8, 2015 (Basel, 2015), the Basel Committee revised the 2010 guidelines (Basel, 2010) on corporate governance principles for banks ("2015 Principles")to reflect corporate governance developments in the financial services industry since the issuance of the 2010 Principles, including the recent work by the Financial Stability Board ${ }^{\mathrm{d}}$ and various regulatory and international agencies following the financial crisis $^{\mathrm{e}}$. The 2015 Principles expand the responsibilities of boards of directors, particularly with respect to overseeing the implementation of effective risk management systems, further define the elements of a robust risk governance framework, with respect to the responsibilities of business units, risk management teams and internal audit (the so-called "three lines of defense"),

\footnotetext{
${ }^{\mathrm{c}}$ This guidance drew from principles of corporate governance that were earlier published by the Organization for Economic Cooperation and Development (OECD, 1999).

${ }^{\mathrm{d}}$ Thematic Review on Risk Governance: Peer Review Report, Financial Stability Board, February 2013.

${ }^{\mathrm{e}}$ For example, the Council of the Organization for Economic Co-Operation and Development recently approved revisions to its OECD Principles for Corporate Governance.

106
} 
Provide guidance for bank supervisors in evaluating the processes used by banking organizations to select board members and senior management, review appropriate compensation structures, that involve acceptable risk-taking behavior and focus on conduct risks and risk culture. The 2015 Principles rely on 13 principles addressing the following topics: board's responsibilities (principles 1), board qualifications and composition (principle 2), board's own structure and practices (principle 3), senior management responsibilities (principle 4), governance of group structures (principle 5), risk management function (principle 6), risk identification, monitoring and controlling (principle 7), risk communication (principle 8), compliance (principle 9), internal audit (principle 10), compensation (principle 11), disclosure and transparency (principle 12), the role of supervisors (principle 13).

As we have underlined, the 2015 Principles pay more attention to culture and conduct risks, with culture referenced more than 10 times more often than in the 2010 Guidelines. The revised version incorporates 2014 FSB guidance on risk culture ${ }^{\mathrm{f}}$. The Principles highlight the need to define conduct risk, which is refers to "cases of misconduct", resulting from the mis-selling of financial products to retail and business clients, the violation of national and international rules (tax rules, anti-money laundering rules, antiterrorism rules, economic sanctions, etc) and the manipulation of financial markets (for instance, the manipulation of Libor rates and foreign exchange rates). The board should provide guidance for market conduct and it has to reinforce corporate culture, by defining, monitoring and reporting on risk culture. It is in charge of establishing the firm's corporate culture and values, while the risk committee is responsible for reporting on the state of risk culture within the bank.

\subsection{The Financial Stability Board Thematic Peer Review on Risk Governance}

The Financial Stability Board Peer Review on Risk Governance, published in 2013, reports the risk governance practices at both national authorities and firms, underlines improvements made after the financial crisis and gives recommendations in order to make further progresses. The peer review shows that, after the financial crisis, national authorities have taken a number of measures to support regulatory and supervisory improvements in the risk governance of financial firms. These measures comprise developing or reinforcing existing regulation or guidelines, engaging more frequently with the board and the management and ascertaining the accuracy and usefulness of the information provided to the board. Anyway, both the national authorities and the supervisors need to better evaluate the effectiveness of a company's risk governance framework and, in particular, its risk culture.

In the peer review there is a survey on 36 banks, brokers and dealers that FSB members considered relevant for the purpose of the review. Their responses show that several of their best risk governance practices are more advanced than national supervisory guidelines. This situation may have been caused by the surveyed firms' need to recover market confidence. Although these relevant improvements, many strides have to be made in several areas, particularly in the risk management function. The report contains a list of sound risk governance practices, that would help both firms to improve their risk governance and national authorities to ascertain its effectiveness. The document formulates also some recommendations addressed to areas where more enhancements are necessary.

It is important to underline that this report is followed by the publication of guidance on assessing risk culture in $2014^{\mathrm{g}}$. In this document, the FSB identifies risk governance, risk appetite, and compensation as the "foundational elements of a sound risk culture." Moreover, national regulators are asked to consider the following indicators of a sound risk culture during their inspections/audits: tone from the top, accountability, effective communication and challenge, and incentives. The FSB recommends that regulators consider these indicators "collectively and as mutually reinforcing" (p. 3) rather than individually. Table 1 shows in detail the four risk culture indicators: tone from the top, accountability, effective communications and challenge, and incentives. Table 1 shows in detail the four risk culture indicators: tone from the top, accountability, effective communications and challenge, and incentives.

\footnotetext{
${ }^{\mathrm{f}}$ Guidance on Supervisory Interaction with Financial Institutions on Risk Culture, Financial Stability Board, 2014.

g Guidance on Supervisory Interaction with Financial Institutions on Risk Culture. A Framework for Assessing Risk Culture, FSB, 7 April 2014.
} 


\section{Table 1 - The FSB risk culture indicators}

\begin{tabular}{|l|l|}
\hline Risk culture indicators & Content \\
\hline Tone from the top & $\begin{array}{l}\text { The board and senior management are the starting point for setting the financial } \\
\text { institution's main values and expectations for the risk culture of the institution, } \\
\text { and their behavior must reflect the supported values. A key value that should be } \\
\text { adopted is the expectation that staff acts with integrity (doing the right thing) and } \\
\text { promptly escalate observed non-compliance within or outside the organisation } \\
\text { (i.e., no surprises approach). The leadership of the institution promotes, monitors, } \\
\text { and assesses the risk culture of the financial institution; evaluates the impact of } \\
\text { culture on safety and soundness; and makes changes where necessary. }\end{array}$ \\
\hline Accountability & $\begin{array}{l}\text { Relevant employees at all levels understand the main values of the institution and } \\
\text { its approach to risk, are capable of performing their prescribed roles, and are } \\
\text { aware that they are held accountable for their actions in relation to the } \\
\text { institution's risk-taking behaviour. Staff acceptance of risk-related goals and } \\
\text { related values is absolutely necessary. }\end{array}$ \\
\hline $\begin{array}{l}\text { Effectivecommunication } \\
\text { and challenge }\end{array}$ & $\begin{array}{l}\text { A sound risk culture promotes an environment of open communication and } \\
\text { effective challenge where decision-making processes encourage a range of } \\
\text { views; allow for testing of current practices; stimulate acritical attitude among } \\
\text { employees; and promote an environment of open and constructive engagement. }\end{array}$ \\
\hline Incentives & $\begin{array}{l}\text { Performance and talent management encourage and reinforce maintenance of the } \\
\text { financial institution's wished risk management behaviour. Financial and non- } \\
\text { financial incentives support the main values and risk culture at all levels of the } \\
\text { institution. }\end{array}$
\end{tabular}

Source: Financial Stability Board, "Guidance on Supervisory Interaction with Financial Institutions on Risk Culture: A Framework for Assessing Risk Culture," April 7, 2014, p. 3.

\subsection{The OECD principles after the crisis}

Also the $\mathrm{OECD}^{\mathrm{h}}$ (2009) identifies weaknesses in corporate governance systems as one of the main causes of the recent global financial crisis: in other words, the crisis was generated by excessive risk-taking, that the risk management models have failed to price correctly and that the remuneration schemes have incentivized rather than discouraged.

In a number of OECD reports dealing with "lessons from the financial crisis" (OECD 2009, 2010), great emphasis is given to four specific topics: remuneration schemes, risk management practices, board performance and shareholder rights. Regarding remuneration schemes, they should be the result of an arm's length negotiation ending with the optimal contract structure, balancing the contrasting interests of managers and shareholders. However, managers are often able to exert an excessive power in setting the level and the conditions for their remuneration. As a result, compensation schemes may have a low pay-per-performance sensitivity, and tend to be asymmetric with a limited downside risk. In addition to this, they are often opaque and not correctly disclosed by the firms. More transparency is needed not only about the structure of the remuneration, but also about the process set in the firm to define this structure (i.e., to declare what is the specific roles of the board, and that of the eventual compensation consultants). Compensations schemes need to be redesigned in order to encourage longterm performance, and establish a balance between fixed and variable components. Non-executive independent board members should have an important role in structuring remuneration systems, which should also be subject to the approval of the annual meeting (the rule known as "say on pay").

Another root of managers' excessive risk-takinghas been identified in the implementation of inadequate risk management models, which have failed to price risk correctly. With reference to risk management practices, some technical assumptions have proven to be unrealistic, leading to unreliable predictions, despite the high level of model sophistication. The inadequacy of risk management models was exacerbated by at least two other circumstances: information about risk exposure did not always reach top management, and when it did, it was not always fully understood because of a lack of banking and financial expertise.

\footnotetext{
${ }^{\mathrm{h}}$ See also Kirkpatrick (2009).
} 
If the inadequacy of risk models is not a corporate governance issue, the correct flow of information inside the firm and the professional requirements of senior managers certainly are. Risk management should gain a more central role in the implementation of the corporate strategy, adopt an enterprise based view (rather than a single business unit approach), and be independent, but in continuous contact with the board, that provides guidance to align corporate strategy, risk appetite and risk management structure. The OECD also underlines that it is necessary to increase risk management disclosure and coverage by corporate governance standard setters.

A key relevant issue is also the performance of the board, in terms of both efficiency and effectiveness. First of all, it is essential that board functions, and hence duties and liabilities, are clearly established. In addition, the OECD underlines that formal independence is a necessary condition for a portion of board members, but it should never be interpreted as a sufficient condition. The choice should be always based also on competence, and it would be nice to identify specific professional requirements and to implement continuous training. In addition, it is considered a good practice to avoid duality (i.e., the coincidence between CEO and chairman).

In the end, the OECD focuses on shareholder rights. Their protection is even more important in time of crisis, when their interests are no more substantially aligned with those of managers as in periods of bull market. The proactive and informed participation of shareholders in corporate decisions should be incentivized, also eliminating barriers to voting, for example with reference to cross-border voting.

On 4-5 September 2015, a revised set of OECD Principles of Corporate Governance was launched at the meeting of G20 Finance Ministers and Central Bank Governors in Ankara. They were subsequently endorsed at the G20 Leaders Summit in Antalya on 15-16 November 2015. The 2015 revision of the Principles addresses the 2004 OECD Principles of Corporate Governance and other emerging issues that are increasingly relevant. It is important to underline that the Principles are non-binding and do not aim at detailed prescriptions for national legislation. Rather, they seek to identify objectives and suggest various means for achieving them. They have been adopted as one of the Financial Stability Board'skey standards for sound financial systems, and have been used by the World Bank Group in more than 60 country reviews worldwide. They also serve as the basis for the guidelines on corporate governance of banks issued by the Basel Committee on Banking Supervision.

The revised Principles maintain many of the recommendations from earlier versions (OECD, 1999; OECD, 2004), as well as introducing some new themes. In some cases, they clarify issues from earlier editions. The OECD states that they focus on publicly traded companies, both financial and non-financial. To the extent they are deemed applicable, they might also be a useful tool to improve corporate governance in companies whose shares are not publicly traded. Moreover, some of the Principles may be more appropriate for larger than for smaller companies, but policymakers may wish to raise awareness of good corporate governance for all companies, including smaller and unlisted companies. The Principles are presented in six different chapters: I) Ensuring the basis for an effective corporate governance framework; II) the rights and equitable treatment of shareholders and key ownership functions; III) Institutional investors, stock markets, and other intermediaries; IV) The role of stakeholders; V) Disclosure and transparency; and VI) The responsibilities of the board.

\section{The EU regulatory framework after the financial crisis}

In response to the financial crisis, the European Commission has drawn two green papers, one on corporate governance in financial institutions and remuneration policies and another on the EU corporate governance framework (European Commission 2010 a, b). Moreover, with reference to the topic of remuneration, the European Commission issued Recommendation 2009/3177/EC regarding the regime for the remuneration of directors of listed companies, and Recommendation 2009/3159/EC, specifically devoted to remuneration policies in the financial services sector. In addition, the final text of the 2013/36/EU Capital Requirements Directive (also known as CRD IV) incorporated detailed provisions on remuneration policies in articles 92-96.

\subsection{The EU Green papers on corporate governance}

In 2010, the European Commission published the Green paper on Corporate governance in financial institutions and remuneration policies (European Commission, 2010a), which, together with its accompanying document (European Commission, 2010b), affirms that even if corporate governance was not a direct cause of the crisis, however, the lack of effective checks and balances contributed significantly to excessive risk-taking by financial institutions. 
The EU observes that, although at the time of the crisis many corporate governance codes and recommendations ${ }^{i}$ were already implemented, the turmoil showed the lack of effectiveness of corporate governance principles in the financial services sector, particularly with regard to banks. To explain this situation, the EU advances several explanations. Firstly, it states that the existing principles were too broad in scope, not sufficiently precise, and without a clear allocation of responsibilities for their implementation, giving too much scope for interpretation and allowing for a "tick the box" approach. A second concern is related to the lack of a clear allocation of roles and responsibilities with regard to implementing the principles, within both the financial institution and the supervisory authority. A third issue refers to the non-binding nature of corporate governance codes and recommendations by international organizations, with the consequent absence of deterrent penalties.

The document analyses the deficiencies and weaknesses in corporate governance by focusing in the following areas: the board of directors, risk management, the role of shareholders, the role of supervisory authorities and the role of auditors. Referring to the board of directors, the crisis revealed its inability to control senior management in an effective way, to identify the nature and the relevance of risk, and to institute a constructive dialogue with supervisory authorities. According to the European Commission, there are several reasons for this failure: board members, and especially (the) non-executive ones, often do not devote sufficient time and resources to the fulfillment of their duties; in addition, they do not have the necessary knowledge and expertise, neither show a sufficient level of diversity and balance in terms of gender, social, cultural and educational background. In addition, many financial institutions did not achieve a severe performance assessment of individual board members or of the board, as a whole. With respect to the second concern, the document points out that also the risk management shows a lack of expertise and an inability to understanding and monitoring the different kinds of risk and to getting the information to the appropriate level in real time. Shareholders relied too much on shorttermism, by causing an excessive risk-taking for the financial institutions and by showing a low interest in the long term soundness of the firm. This passive behavior can be explained by some reasons, such as the possession of highly diversified investment portfolios, making too expensive an active engagement in the bank's governance, together with some restrictions to voting rights. At the end, supervisory authorities and auditors have not been adequately effective in identifying and monitoring corporate governance weaknesses.

The Green Paper on the EU corporate governance framework (European Commission, 2011) reaches similar conclusions. Unlike the June 2010 Green Paper, which specifically addresses to financial institutions, this document refers to listed institutions, both financial and non-financial, as some relevant concerns, such as shareholder engagement, matter not just to financial institutions, but to companies generally. As a consequence, the solutions envisaged in the June 2010 Green Paper may not be relevant to EU companies in general. Specifically, the document identifies three subjects as a good performance indicators ("at the heart of corporate governance"): 1) a performing board of directors, in which independent non-executive directors, highly diversified for skill, expertise, gender and background, spend sufficient time and resources to their duties and are able to challenge executive management; 2) engaged shareholders, focusing on the long term performance of the firm and actively participating in main decisions; 3 ) an efficient "comply or explain" approach in order to support the EU corporate governance framework. To this regard, the European Commission argues that, although the Directive 2006/46/EC provisions require that all listed companies refer in their corporate governance statement to a code, explaining which parts of this code they depart from and why, however these explanations are often unsatisfactory and there is no sufficient supervision on the application of national corporate governance codes.

\subsection{The EU Recommendations on corporate governance}

In its Communication of 4 March 2009, the European Commission states that there are two most urgent issues to deal with: the first one refers to the reform of compensation policies, in order to avoid excessive risk-taking and short-termism in financial institutions, while the second one relates to a detailed analysis of current corporate governance practices, to identify further weaknesses and make recommendations, including legislative initiatives, where appropriate. With reference to the topic of remuneration, the EU published two recommendations in April 2009: Recommendation 2009/3177/EC, complementing Recommendations 2004/913/EC and 2005/162/EC and focusing on the compensation regime of directors of listed companies, and Recommendation 2009/3159/EC,

\footnotetext{
${ }^{\mathrm{i}}$ The document refers to OECD principles, the recommendations of the Basel Committee and the Directive 2006/46/EC, which requires financial institutions listed on regulated markets to draw up a corporate governance code to which they are subject, and to indicate any parts of the code from which they have departed and the reasons for doing so.

110
} 
specifically addressed to remuneration policies in the financial services sector. The 2004 and 2005 recommendations contain provisions aimed at guaranteeing both transparency of remuneration policies and increase shareholder control on them; moreover, they establish effective and independent supervision by nonexecutive directors and require the institution to have a remuneration committee, with at least an advisory role.

Recommendation 2009/3177/EC focuses on the remuneration regime of listed companies' directors. Section I, devoted to remuneration policy, states that compensation should be composed both of a fixed and a variable component, with specific limits for the latter, which, consistently with the long-term interests of the firm, should be based on well-identified and measurable performance criteria, both financial and non-financial. In addition, the part of the floater component, that should be deferred for a minimum period of time, so that related risks have time to occur, should be calculated in relation to the relative weight of the variable component compared to the fixed component of remuneration. The variable components assigned on the basis of data that subsequently proves to be misstated, may be claimed back by the firm, and termination payment is not due in case of bad performance. Moreover, termination payments should not exceed a fixed amount and should not be higher than two years of fixed remuneration. Regarding equity-based compensation, shares should not vest for at least three years after their award; in addition, share options (or any other similar right) should not be exercisable for at least three years after their award. Furthermore, a portion of these shares should be retained until the end of the mandate: the example given in the Recommendation is twice the value of total annual remuneration (the nonvariable plus the variable components).At the end, share options should not be recognized to non-executive directors. With regard to the disclosure of the policy on directors 'remuneration, the recommendation establishes that the remuneration statement, an independent document that should be included in the annual accounts and annual reports or in the notes to the annual accounts of the company, should be clear and easily understandable. Referring to the shareholders' vote, and in particular institutional shareholders, it argues that they should be encouraged to attend general meetings and exert their voting rights, as established in the 2004 and 2005 recommendations (that introduced a mandatory or advisory vote on the remuneration statement and explicit shareholder approval for share-based remuneration schemes ${ }^{j}$ ).Section II contains provisions dealing with the remuneration committee, in charge of periodically reviewing the remuneration policy and reporting to the annual general meeting. In order to ensure competence and independence in the exercise of these functions, at least one member of the remuneration committee should have specific expertise in the field of remuneration policy; moreover, the committee should guarantee that there are no conflicts of interest with other activities undertaken by the consultants, when it makes recourse to external advisors.

The Recommendation 2009/3159/EC sets out general principles for all financial firms, both listed and unlisted. It consists of five sections, three of which are respectively devoted to remuneration policy (Section II), disclosure (Section III) and supervision (Section IV).Even if the main structure of remuneration is quite similar to that designed in the Recommendation 2009/3177/EC, in the case of financial undertakings, there are some peculiarities that are worth to be noticed. First of all, the recommendation refers also to the remuneration of each category of staff, whose professional activities have a material impact on the risk profile of the financial undertaking. The relevance of the risk concern is visible also in other provisions: e.g., it is required that performance is measured including an adjustment for related current and future risks, taking into account the cost of the capital employed and the liquidity required. This assessment may be conducted with a comprehensive view of both the individual performance and that of the concerned business unit. Section III states that the disclosure of the relevant information on the remuneration policy information may take the form of an independent remuneration policy statement, which should include: a) information concerning the decision-making process used for determining the remuneration policy, including, if applicable, information about the composition and the mandate of a remuneration committee, the name of the external consultant whose services have been used for the determination of the remuneration policy and the role of the relevant stakeholders; b) information on the linkage between pay and performance; (c) information on the criteria used for performance measurement and the risk adjustment; (d) information on the performance criteria on which the entitlement to shares, options or variable components of remuneration is based; (e) the main parameters and rationale for any annual bonus scheme and any other non-cash benefits.

\footnotetext{
${ }^{\mathrm{j}}$ The approval relates to the scheme of remuneration, not to the individual remuneration of directors under the scheme.
} 


\subsection{The CRD IV framework on banking corporate governance}

One year after the issue of recommendations on remuneration policies, the European Commission published two reports (European Commission, 2010c, 2010d) on their implementation across Member States, arguing that, as there was a relatively high number of Member States that did not take sufficient measures especially in the financial services sector, it would proceed with further interventions to guarantee a common approach in all the Union.

The final text of the 2013/36/EU Capital Requirements Directive (also known as CRD IV) contains specific provisions regarding board composition, risk management and remuneration policies of banks and investment firms. Article 74, dealing with internal governance and recovery and resolution plans, requires banks and investment firms having: robust governance arrangements, effective processes to identify, manage, monitor and report the risks the institutions are or might be exposed to, adequate internal control mechanisms and remuneration policies and practices that are consistent with and promote sound and effective risk management. The above-mentioned arrangements, processes and mechanisms have to be proportionate to the nature, scale and complexity of the risks of the business model and the institution's activities. The third paragraph of the article refers to the guidelines that will be issued by the European Banking Authority, while the fourth one assigns to supervisory authorities the task of ensuring that recovery and resolution plans are put in place. Article 75 contains an oversight of remuneration policies, that are discussed in more detail in articles 92-96.Article 76 comprises specific provisions on the treatment of risks. It states that the management body is responsible for managing, monitoring and mitigating both microeconomic and macroeconomic risks. While significant institutions, in terms of size, internal organization and the nature, scope and complexity of activities, are required to establish a risk committee, composed of skilled non-executive directors, that assists the management body in setting and implementing the risk appetite and strategy of the institution, competent authorities may allow a not significant institution to combine the risk committee with the audit committee. Member States shall ensure that the management body in its supervisory function and, where a risk committee has been established, the risk committee have adequate access to information on the risk situation of the institution and, if necessary and appropriate, to the risk management function and to external expert advice. Furthermore, the risk management function shall be independent from the operational functions, with sufficient authority, stature, resources and access to the management body. It is involved in the elaboration of the risk strategy and in all material risk management decisions. The head of risk management is an independent senior manager with a distinct responsibility for the risk management function. In small institutions, another senior person within the company may fulfill that task, if there is no conflict of interest. In any case, the head of the risk management function has direct access to the management body in its supervisory function, and cannot be removed without its prior approval. The articles from 77 to 87 focus on internal approaches for calculating own funds requirements and on provisions referring to several types of risks (credit and counterparty risk, residual risk, concentration risk, securitization risk, market risk, interest risk arising from non-trading book activities, operational risk, liquidity risk and risk of excessive leverage). In sub-section 3, entitled "Governance", the document addresses more strictly to corporate governance features. Article 88 (Governance arrangements) states that the management body has the overall responsibility for the implementation of the institution's strategic objectives, risk strategy and internal governance; it is also responsible for the integrity of the accounting and financial reporting systems, for the oversight of senior management, and for disclosure and communication processes. Duality of chief executive officer and chairman of the management body is not allowed unless justified by the institution and authorized by competent authorities. The management body shall periodically review and assess the effectiveness of governance arrangements and take appropriate measures to overcome any deficiencies. The article includes also several provisions on the nomination committee. In particular, it requires large and complex institutions to have a nomination committee composed of non-executive directors, assisting the management body in the identification of appropriate candidates to fill vacancies, in the settlement of a target for the representation of the underrepresented gender in the management body, in the assessment of the structure, size, composition and performance of the management body, and in the evaluation of skills and competences of individual members.

Article 91 (Management body) includes some requirements for board members, in order to guarantee their commitment, good repute, sufficient knowledge, skills and experience. There are also limitations to the number of directorships which may be held at the same time. 
Specifically, the article states that from 1 July 2014 board members of large and complex organization can hold, at maximum, one executive directorship with two non-executive directorships, or four non-executive directorships $^{\mathrm{k}}$. Competent authorities may allow members of the management body to hold one additional nonexecutive directorship and regularly inform EBA of such authorizations. Other provisions establish that the management body in its supervisory function shall act with honesty, integrity and independence of mind. In addition, it states EBA would have issued, by 31 December 2015, guidelines regarding the notions of sufficient time commitment, adequate collective knowledge, skills and experience, honesty, integrity and independence of mind and diversity.

\section{Conclusions}

It is now possible to draw some conclusions about the regulatory standpoint on banking corporate governance. First of all, it is important to outline that the regulatory intervention has been mainly guided by the idea that financial institutions are systemically relevant, i.e., that their crisis may spread contagion to financial markets and then to the whole economy. Secondly, we outline that another common choice has been a prompt regulatory response in order to overcome the main corporate governance weaknesses developed during the crisis, with a specific focus on remuneration policies and risk management.

Remuneration is a key feature of the re-regulation process, since it can be considered as a fundamental step in rebuilding trust between the public and financial institutions. To this extent, with respect to banks and investment companies, the intervention has been significant, by incorporating corporate governance requisites in the prudential regulation. Thirdly, we point out that the regulatory response to the financial crisis has led both to nonbinding rules, developed by international organizations, and binding rules issued by regulatory authorities. Fourthly, we can state that rules proposed by international organizations, irrespective of the specific entity that issued them, show some common characteristics. Although they are not compulsory, they have become a relevant reference for regulators and supervisors; they are projected to align the interest of managers and shareholders, by taking into account also other stakeholders, such as policyholders, employees, debt-holders, etc.; they aim at reducing perverse incentives towards excessive risk-taking; they do not prescribe strict requisites for each corporate governance issue, for example they do not require a particular model and structure of the boards or a specific design for remuneration schemes. Finally, it is possible to conclude that, observing the more recent regulatory interventions dealing with corporate governance after the global financial crisis, a rule-based approach is prevailing on the lighter principle-based approach"

On the one hand, a principle-based approach is more flexible and more prone to adapt to specific profiles, implying greater levels of freedom that may be abused by some market participants and may also complicate the implementation, for both firms and supervisors. On the other hand, a rule-based approach generally is based on the idea that "one size fits all". After the financial crisis, there has been a transition from the first to the second approach, as it is likely that most regulators are willing to sacrifice flexibility and innovation in order to contrast excessive discretion, arbitrage and complex enactment of their rules.

\section{References}

Basel Committee on Banking Supervision (2010). Principles for enhancingcorporate governance, October 2010.

Basel Committee on Banking Supervision (2014). Corporate governanceprinciples for banks, October 2014.

Basel Committee on Banking Supervision (2015). Corporate governanceprinciples for banks, July 2015.

Committee of European Banking Supervisors (2009). CEBS Principles on RemunerationPolicies and Practices, April 2009.

Committee of European Banking Supervisors (2010). CEBS Guidelines on RemunerationPolicies and Practices, December 2010.

European Banking Authority (2011). EBA Guidelines on InternalGovernance, September 2011.

\footnotetext{
${ }^{\mathrm{k}}$ The article specifies that executive or non-executive directorships held within the same group, or within institutions which are members of the same institutional protection scheme, or undertakings (including non-financial entities) in which the institution holds a qualifying holding, count as a single directorship. Directorships in organisations which do not pursue predominantly commercial objectives shall not count.

${ }^{1}$ See O. Ricci (2014).
} 
EuropeanCommission (2010a). Green Paper. Corporate governance in financialinstitutions and remunerationpolicies, Brussels, 2.6.2010, COM(2010) 284 final.

EuropeanCommission (2010b). Commission Staff WorkingDocument. Corporate governance in financialinstitutions: Lessons to be drawn from the currentfinancialcrisis, best practices. Accompanyingdocument to the Green Paper on corporate governance in financialinstitutions and remunerationpolicies, Brussels, 2.6.2010, SEC(2010) 669.

EuropeanCommission (2010c). Report on the application by MemberStates of the EU of the Commission 2009/385/EC Recommendation (2009 Recommendation on directors' remuneration) complementingRecommendations 2004/913/EC and 2005/162/EC asregards the regime for the remuneration of directors of listed companies, Brussels, 2.6.2010, SECS(2010) 670.

EuropeanCommission (2010d). Report on the application by MemberStates of the EU of the Commission 2009/384/EC Recommendation on remunerationpolicies in the financialservices sector (2009 Recommendation on remunerationpolicies in the financialservicessector), Brussels, 2.6.2010, SECS(2010) 671.

EuropeanCommission (2011). Green Paper. The EU corporate governance framework, Brussels, 5.4.2011, COM(2011) 164 final.

Financial Stability Board (2013).ThematicReview on RiskGovernance, February 2013.

Financial Stability Board (2014). Guidance on Supervisory Interaction with Financial Institutions on Risk Culture. A Framework for Assessing Risk Culture, April 2014.

Hopt, K. J. (2013). Corporate Governance of Banks and Other Financial InstitutionsAfter the Financial Crisis, Journal of Corporate Law Studies Volume 13, pp. 219-253.

Kirkpatrick, G. (2009). The corporate governance lessons from the financial crisis, Financial Market Trends, Vol. 2009, No. 1, pp. 1-30.

Organization for Economic Co-operation and Development (OECD) (1999). OECD principles of corporate governance, 1999.

Organization for Economic Co-operation and Development (OECD) (2004). OECD principles of corporate governance, 2004.

Organization for Economic Co-operation and Development (OECD) (2009). Corporate governance and the financial crisis. Key findings and main messages, June 2009.

Organization for Economic Co-operation and Development (OECD) (2010). Corporate governance and the financial crisis. Conclusions and emerging good practices to enhance implementation of the Principles, 24 February 2010.

Organization for Economic Co-operation and Development (OECD) (2015). G/20 OECD principles of corporate governance, September 2015.

Ricci O. (2014). Corporate Governance in the European Insurance Industry. Palgrave Macmillan.

\section{Regulation}

Recommendation 2004/913/EC (Commission Recommendation of 14 December 2004 Fostering an Appropriate Regime for the Remuneration of Directors of Listed Companies).

Recommendation 2005/162/EC (Commission Recommendation of 15 February 2005 on the Role of Non-Executive or Supervisory Directors of Listed Companies and on the Committees of the (Supervisory) Board).

Directive 2006/46/ECof the European Parliament and of the Council of 14 June 2006 Amending Council Directives 78/660/EECon the Annual Accounts of Certain Types of Companies, 83/349/EECon Consolidated Accounts, 86/635/EECon the Annual Accounts and Consolidated Accounts of Banks and Other Financial Institutions and 91/674/ECon the Annual Accounts and Consolidated Accounts of Insurance Undertakings.

Recommendation 2009/3159/EC (Commission Recommendation of 30 April 2009 on Remuneration Policies in the Financial Services Sector).

Recommendation 2009/3177/EC (Commission Recommendation of 30 April 2009 Complementing Recommendations 2004/913/ECand 2005/162/ECas Regards the Regime for the Remuneration of Directors of Listed Companies).

Directive 2013/36/EUof the European Parliament and of the Council of 26 June 2013 on Access to the Activity of Credit Institutions and the Prudential Supervision of Credit Institutions and Investment Firms, Amending Directive 2002/87/ECand Repealing Directives 2006/48/ECand 2006/49/EC. 